\title{
Neuronal Tryptophan Hydroxylase mRNA Expression in the Human Dorsal and Median Raphe Nuclei: Major Depression and Suicide
}

\author{
Helene Bach-Mizrachi',2, Mark D Underwood ',2, Suham A Kassir', Mihran J Bakalian', Etienne Sibille',2,4, \\ Hadassah Tamir ${ }^{1,2,3}$, J John Mann ${ }^{1,2}$ and Victoria Arango*, I,2 \\ 'Department of Neuroscience, New York State Psychiatric Institute, New York, NY, USA; ${ }^{2}$ Department of Psychiatry, Columbia College \\ of Physicians and Surgeons, New York, NY, USA; ${ }^{3}$ Department of Anatomy and Cell Biology, Columbia College of Physicians and Surgeons, \\ New York, NY, USA
}

\begin{abstract}
Major depressive disorder (MDD) and suicide are associated with deficient serotonergic neurotransmission. Tryptophan hydroxylase $(\mathrm{TPH})$ is the rate-limiting biosynthetic enzyme for serotonin. Previously, we reported elevated levels of TPH protein in the dorsal raphe nucleus (DRN) of depressed suicides and now examine expression of neuronal TPH2 mRNA in a cohort of matched controls and depressed suicides $(n=11$ pairs). DRN TPH2 mRNA was measured by densitometric analysis of autoradiograms from in situ hybridization histochemistry experiments. TPH2 mRNA is confirmed as the raphe-specific isoform of TPH in human brain, and is expressed in neurons throughout the anteroposterior extent of the DRN and median raphe nucleus (MRN). TPH2 mRNA expression correlates with TPH protein distribution in the DRN, and has a negative correlation with age. In drug-free suicides, TPH2 expression is $33 \%$ higher in the DRN and 17\% higher in the MRN as compared to matched nonpsychiatric controls. Higher levels of TPH2 mRNA were found throughout the entire extent of the rostrocaudal axis of the DRN, and were not specific to any single subnucleus. Higher TPH2 mRNA expression may explain more TPH protein observed in depressed suicides and reflect a homeostatic response to deficient brain serotonergic transmission.
\end{abstract}

Neuropsychopharmacology (2006) 31, 8|4-824. doi:I0. I038/sj.npp. I 300897; published online 28 September 2005

Keywords: serotonin; serotonin synthesis; in situ hybridization histochemistry; postmortem

\section{INTRODUCTION}

Suicide is the 11th leading cause of death in the United States across all age groups, the third leading cause in the 10-24 years of age group and second in people between the ages of 25 and 35 (www.cdc.gov/ncipc/wisqars 2002). Mood disorders are strongly associated with suicidal behavior, with an estimated $60 \%$ of completed suicides having a lifetime diagnosis of mood disorder (Mann, 2003; Turecki et al, 2001). Extensive evidence implicates the brain serotonergic system in major depression and suicide. More than 20 studies have reported a correlation between low levels of cerebrospinal fluid 5-hydroxyindoleacetic acid

\footnotetext{
* Correspondence: Professor $\vee$ Arango, Department of Neuroscience, New York State Psychiatric Institute, 1051 Riverside Drive, Box 42, New York, NY I0032, USA, Tel: + I 212543 5440, Fax: + I 212543 6017, E-mail: varango@neuron.cpmc.columbia.edu

${ }^{4}$ Current address: Department of Psychiatry, Western Psychiatric Institute and Clinic, University of Pittsburgh, Pittsburgh, PA, USA Received 10 February 2005; revised 5 August 2005; accepted II August 2005

Online publication: 18 August 2005 at http://www.acnp.org/citations/ Npp081805050086/default.pdf
}

(5-HIAA) and suicidal behavior (reviewed by Placidi et al, 2001). Postmortem studies of depression and suicide report low levels of serotonin and/or 5-HIAA in the brainstem of suicides with or without major depression (Mann et al, 1989). Neuroendocrine studies find blunted serotoninmediated prolactin release related to aggressive and suicidal behavior (see Dulchin et al, 2001; Malone et al, 1996; Weiss and Coccaro, 1997). Furthermore, in postmortem serotonin receptor-binding studies, presynaptic alterations are identified in the brainstem (Arango et al, 2001) and pre- and postsynaptic alterations are described in the prefrontal cortex (Arango et al, 1995; Hrdina et al, 1993; Mann et al, 2000; Pandey et al, 2002).

Most of the serotonin in the forebrain is produced by neurons in the dorsal and median raphe nuclei (DRN and MRN, respectively) in the rostral brainstem (Törk, 1990). In primates, the serotonin-synthesizing neurons of these rostral raphe nuclei send projections throughout the cerebrum, but importantly to the prefrontal cortex (Pierce et al, 1976; Wilson and Molliver, 1991a,b). In serotonin neurons, tryptophan hydroxylase (TPH) is the rate-limiting enzyme in the biosynthesis of serotonin. Despite much investigation of the serotonergic system in suicide and 
depression, measurement of the TPH gene or protein expression level in the brain has been rarely reported.

At the transcript level, brain serotonin in rodents is regulated by a neuron-specific isoform of TPH, known as TPH2 (Patel et al, 2004; Zhang et al, 2004). Until the recent discovery of TPH2 (Walther et al, 2003), quantitative studies of TPH gene expression in brain had been hampered by the seemingly almost undetectable level of transcript expression in the raphe (Austin and O'Donnell, 1999; Clark and Russo, 1997). These studies were unknowingly measuring peripheral TPH (TPH1), the non-neuronal isoform of the enzyme (Walther et al, 2003).

At the protein level, we reported greater density and number of TPH-immunoreactive (TPH-IR) neurons in the DRN of suicides relative to normal controls (Underwood et al, 1999), suggesting that the serotonergic deficiency in suicide is not due to fewer serotonin-synthesizing neurons in the DRN or due to less TPH protein. Other reports have found fewer number of neurons in the DRvl subnucleus of patients with mood disorders (Baumann et al, 2002) and no change in TPH immunoreactivity in any of the DRN subnuclei of depressed suicides (Bonkale et al, 2004). However, these studies did not quantify systematically the entirety of the DRN, or lacked specificity by not limiting counts to serotonergic neurons. Furthermore, we have confirmed our finding of higher TPH immunoreactivity in a second cohort of suicides and controls using immunoautoradiography (Boldrini et al, 2005). Further evidence of disordered function in DRN neurons of suicide subjects includes altered 5- $\mathrm{HT}_{1 \mathrm{~A}}$ autoreceptor binding (Arango et al, 2001; Stockmeier et al, 1998), and both less serotonin transporter binding and expression (Arango et al, 2001). The combination of postmortem studies reporting low serotonin/5-HIAA midbrain levels in suicide, and in vivo studies reporting low CSF 5-HIAA in suicide attempters (Placidi et al, 2000), combined with postmortem findings of greater DRN TPH-IR neuron density, more TPH protein, and fewer transporter sites, suggests upregulation of biosynthetic capacity and putative transporter internalization in response to less serotonin.

To determine whether more $\mathrm{TPH}$ protein in depressed suicides is associated with increased TPH2 mRNA gene expression, we measured the expression of TPH2 mRNA in the DRN and MRN of depressed suicides compared to matched psychiatrically normal controls. We analyzed DRN subnuclei to determine the anatomical distribution of TPH2 message in depressed suicide cases.

\section{MATERIALS AND METHODS}

\section{Subjects}

Tissue was provided by the Allegheny County Coroner and the NYC Medical Examiner's Office, with protocols approved by all applicable Institutional Review Boards. The next of kin consented to tissue collection, review of relevant records, and a psychological autopsy (see Mann et al, 2000) for description of psychological autopsy procedures). All cases died suddenly. Subject demographics are presented in Table 1. Control cases died of causes other than suicide and had no Axis I or Axis II psychiatric diagnosis based on a structured clinical interview (SCID I and II; First et al, 1996; Kelly and Mann, 1996; Spitzer et al, 1992; Williams et al, 1992). In all, 10 suicides had an Axis I diagnosis of major depression, one of which had a diagnosis of major depression as part of a schizoaffective disorder. Comorbidities included one case with an eating disorder and one with obsessive-compulsive disorder. One case with schizoid personality disorder was suspected to have major depression, but failed to meet DSM criteria. Brain collection, neuropathology, toxicology, and tissue-sectioning protocols are described elsewhere (Arango et al, 2001). Postmortem interval, defined as the time of death to time of freezing the brain tissue, averaged $16.6 \mathrm{~h}$. Brain $\mathrm{pH}$ was measured from cerebellar tissue and was $6.44 \pm 0.12$ in controls and $6.63 \pm 0.08$ in suicides $(p>0.05)$. Studies of normal TPH2 mRNA distribution were performed on sections from a total of 13 control cases. Experiments designed for comparing depressed suicides and controls were performed in 11 matched case-control pairs. Cases were matched for age \pm 5 years (C: $56 \pm 5$ vs S: $57 \pm 5$ year), sex (C: nine males:two females vs $\mathrm{S}$ : nine males: two females), race (C: seven Caucasian, one Hispanic, three African American vs S: six Caucasian, five Hispanic), and $\mathrm{PMI} \pm 5 \mathrm{~h}$ (C: $13 \pm 1.5$ vs S: $19 \pm 1.6)$. Manners of suicide were hanging $(n=6)$, fall from height $(n=3)$, gun shot $(n=1)$, and drowning $(n=1)$. The causes of death in the controls were: acute myocardial infarction $(n=9)$, motor vehicle accident (pedestrian, $n=2$ ), motor vehicle accident (passenger, $n=1)$, and industrial accident $(n=1)$. Four depressed subjects were reported to have received prescriptions for psychotropic medication within the three months before death (SSRIs, $n=2$; mood stabilizers, $n=1$; tricyclic antidepressants, $n=1$ ). However, all cases had clear peripheral and brain toxicological screens at the time of death.

\section{Brainstems}

Brains were collected at autopsy. The brainstem was isolated by a transverse cut along the rostral border of the superior colliculus and a second cut through the middle cerebellar peduncle. The block was approximately $3 \mathrm{~cm}$ in length, encompassed the midbrain and rostral pons, and contained the DRN and MRN. The block was flash-frozen in Freon $\left(-20^{\circ} \mathrm{C}\right)$ and stored at $-80^{\circ} \mathrm{C}$ until sectioning. Transverse sections were cut in a cryostat at $20 \mu \mathrm{m}$ thickness, mounted on subbed glass slides, and stored at $-80^{\circ} \mathrm{C}$ until assayed. $\mathrm{pH}$ was measured in cerebellar tissue (Harrison et al, 1995) to assess integrity of the RNA. Tissue sections for in situ hybridization assay were collected approximately every millimeter throughout the rostrocaudal extent of the DRN, corresponding to 16-20 sections per case. Sets of adjacent sections from each case, assayed for TPH protein with biotinylated-PH8 (Boldrini et al, 2005) and $\left[{ }^{3} \mathrm{H}\right] 8-\mathrm{OH}-\mathrm{DPAT}$ (a $5-\mathrm{HT}_{1 \mathrm{~A}}$ receptor agonist (Arango et al, 2001), were used to identify boundaries of the raphe nuclei and to further delineate DRN subnuclei for the analysis of TPH2 mRNA in in situ hybridization autoradiograms.

\section{Riboprobe Preparation}

Riboprobes specific for TPH2 were generated by RT-PCR from human RNA. Human total RNA was extracted from 
Table I Case Demographics

\begin{tabular}{|c|c|c|c|c|c|c|c|c|c|c|}
\hline Pair \# & Age & Sex & Race & PMI & $\mathrm{pH}$ & Storage time & Brain toxicology & Axis I & Cause of death & Antemortem prescriptions \\
\hline । & 66 & Male & White & 19 & 6.1 & 3514 & None & None & Heart attack & None \\
\hline la & 63 & Male & Hispanic & 17 & 6.74 & 2706 & None & None & Hanging (S) & None \\
\hline 2 & 30 & Female & African-American & 8 & 6.73 & 2755 & None & None & Heart attack & None \\
\hline $2 a$ & 26 & Female & Hispanic & 18 & 6.88 & 2799 & None & Schizoaffective, depressed type & Hanging (S) & Mood stabilizers \\
\hline 3 & 79 & Male & White & 9.75 & 5.957 & 4870 & Lidocaine/antiarrythmic & None & Heart attack & None \\
\hline $3 a$ & 77 & Male & White & 18 & 6.396 & 4909 & None & MDD & Hanging (S) & None \\
\hline 4 & 27 & Female & White & 15 & 6.717 & 4314 & None & None & MVA & None \\
\hline $4 a$ & 28 & Female & White & 19 & 6.32 & 4547 & None & Eating disorder, MDD & Fall from height (S) & TCA \\
\hline 5 & 51 & Male & Hispanic & 7.5 & NA & 4867 & None & None & Heart attack & None \\
\hline $5 a$ & 66 & Male & White & 11 & NA & 4846 & Caffeine & None & Gun shot (S) & None \\
\hline 6 & 53 & Male & White & 18.5 & NA & 3898 & None & None & Heart attack & None \\
\hline $6 a$ & 50 & Male & Hispanic & 30 & 6.82 & 3089 & None & MDD & Fall from height (S) & None \\
\hline 7 & 37 & Male & African-American & 15 & 6.75 & 2715 & None & None & Heart attack & None \\
\hline $7 a$ & 40 & Male & White & 20 & 6.77 & 2607 & Analgesics & MDD & Hanging (S) & SSRI \\
\hline 8 & 85 & Male & White & 7 & NA & 4200 & None & None & Heart attack & None \\
\hline $8 a$ & 74 & Male & White & 21 & NA & 4168 & Opiates, analgesics, caffeine & MDD & Fall from height (S) & None \\
\hline 9 & 53 & Male & African-American & 9 & NA & 1905 & None & None & Industrial accident & None \\
\hline $9 a$ & 59 & Male & Hispanic & 24.5 & 6.77 & 2546 & None & MDD & Hanging $(S)$ & None \\
\hline 10 & 58 & Male & White & 22 & 6.44 & 2188 & Anesthetics & None & Heart attack & None \\
\hline $10 \mathrm{a}$ & 62 & Male & White & 21 & 6.37 & 1950 & None & MDD & Drowning (S) & SSRI \\
\hline 11 & 56 & Male & White & 14 & 6.41 & 1463 & Caffeine & None & Heart attack & None \\
\hline Ila & 56 & Male & Hispanic & 21 & 6.56 & 335 & None & MDD & Hanging (S) & None \\
\hline 12 & 36 & Male & White & 14 & NA & 4257 & $\mathrm{CO}$ & None & MVA & None \\
\hline 13 & 40 & Female & White & 26 & NA & 2426 & None & None & MVA & None \\
\hline Mean & 53 & & & 16.9 & 6.55 & 3245 & & & & \\
\hline SEM & 4 & & & 1.2 & 0.07 & 254 & & & & \\
\hline
\end{tabular}

All demographic information was made available by the medical examiner and psychological autopsy provided by next of kin.

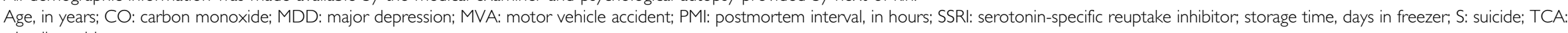
tricyclic antidepressants. 
frozen sections using Trizol reagent (Invitrogen, Carlsbad, CA). These sections were cut at $60 \mu \mathrm{m}$ and stored in Eppendorf tubes at $-80^{\circ} \mathrm{C}$ for later mRNA isolation. mRNA was reverse transcribed into cDNA using SuperScript II Reverse Transcriptase (Invitrogen, Carlsbad, CA), which was subsequently used for PCR. TPH2-specific primers for PCR were generated from the published human cDNA sequence (Walther et al, 2003) available on Genbank (accession number: AY098914). The forward primer sequence was $5^{\prime}$-CTCTCCAAACTCTATCCCACT- $3^{\prime}$ and the reverse primer sequence was $5^{\prime}$-AGGCATCAAATCCCC AGA- $3^{\prime}$. These primers were designed from a region of the transcript that is conserved across species (human, rat, and mouse).

PCR cycling conditions were as follows: $90^{\circ} \mathrm{C}$ denaturing temperature for $30 \mathrm{~s}$, ramping down to $50^{\circ} \mathrm{C}$ annealing temperature for $15 \mathrm{~s}$, and then $72^{\circ} \mathrm{C}$ for $15 \mathrm{~s}$. These cycling parameters were repeated for 30 cycles. The resulting 800 base pair product was purified and cloned into the PCRII-TOPO vector (Invitrogen, Carlsbad, CA). The TPH2-containing plasmids were transformed into Escherichia coli, grown overnight, extracted, and purified. The resulting construct was linearized with HindIII and transcribed with SP6 RNA polymerase (Promega Madison, $\mathrm{WI})$ to generate a specific TPH2 antisense probe. The control sense probe was created by linearizing the same construct with $X b a \mathrm{I}$, and transcribing with T7 RNA polymerase. The sequences of both probes were verified. Riboprobes were labeled with $\left.{ }^{35} \mathrm{~S}\right] \mathrm{rCTP}$ (Perkin-Elmer, Boston, MA) by adding the radiolabeled nucleotide to the in vitro transcription reaction. The probe was then passed through a spin column (RNeasy Kit from Qiagen, Valencia, CA) to remove all unincorporated nucleotides. Probespecific activity was determined by measuring the counts per minute (cpm) in an aliquot of the purified probe using a scintillation counter. Incorporation of radioactive nucleotide was determined by taking scintillation counts of labeled reaction before and after removal of unincorporated nucleotides.

\section{In Situ Hybridization Histochemistry}

In situ hybridization experiments were carried out in two phases on tissue sections of brainstems from 11 pairs of matched suicide and control cases. First, in order to compare the expression of TPH 2 mRNA in all subjects, two tissue sections from a midcaudal level of the DRN (see Figure 1) from each case were assayed together in a single experiment. The use of the same solutions and probe preparation and exposure to the same autoradiographic film in a single cassette controlled for all possible interassay variables. The midcaudal level of the DRN was selected because it has a relatively homogeneous composition of the DRN (ie without representation of multiple subnuclei within a single section), and to be comparable and available between all subjects. In the second phase, sections spanning the rostrocaudal extent of the DRN and MRN from each matched pair were assayed together with the same solutions to reduce experimental variability within the pair. The assay throughout the anatomical extent of the raphe allows for the determination of the distribution and localization of TPH2 mRNA in the DRN between groups. a
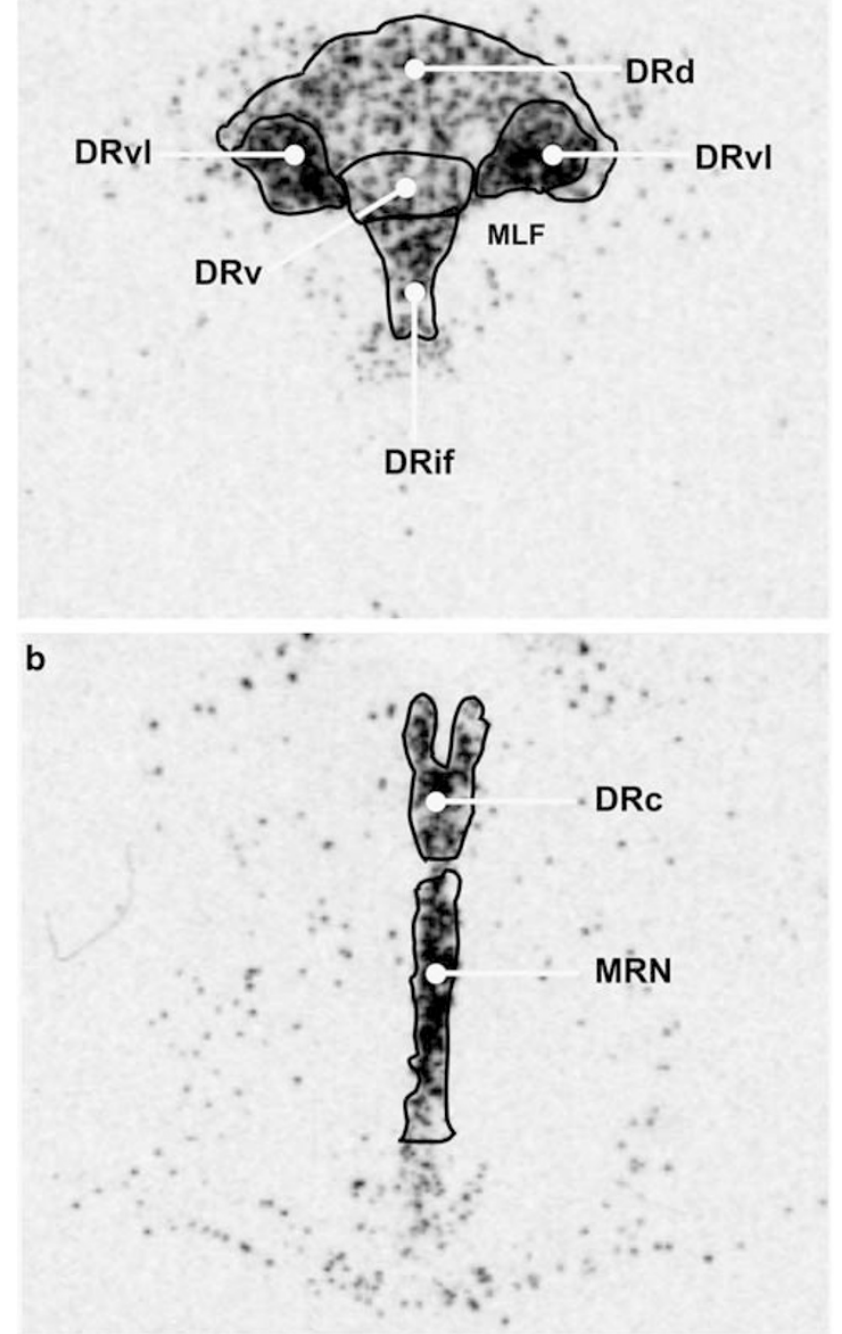

Figure I (a) Schematic of DRN subnuclei. The sampled subnuclei are outlined in black and include the dorsal (DRd), ventral (DRv), ventrolateral (DRvl), and interfascicular (DRif) subnuclei. In (b), the caudal subnucleus (DRc) is outlined in a more caudal section of the DRN. The medial longitudinal fasciculus (MLF) is labeled in the rostral section.

Sections were brought to room temperature and dried under vacuum. Sections were fixed in $4 \%$ paraformaldehyde in $0.1 \mathrm{M}$ PBS ( $\mathrm{pH} 7.4$ ) for $15 \mathrm{~min}$, rinsed in PBS for $5 \mathrm{~min}$, and acetylated in $0.25 \%$ acetic anhydride in $0.1 \mathrm{M}$ triethanolamine, $\mathrm{pH} 8.0$ for $10 \mathrm{~min}$. Then sections were dehydrated through increasing concentrations of ethanol, delipidated in chloroform for $10 \mathrm{~min}$, washed in 100 and $95 \%$ ethanol for $1 \mathrm{~min}$ each, and covered with $100 \mu \mathrm{l}$ of hybridization solution $(50 \%$ formamide, $10 \mathrm{mM}$ EDTA, $20 \mathrm{mM}$ Pipes, $0.75 \mathrm{M} \mathrm{NaCl}, 10 \%$ dextran sulfate, $5 \times$ Denhardts, $250 \mu \mathrm{l} / \mathrm{ml}$ tRNA, and denatured radiolabeled probe $\left(3 \mathrm{ng}, 2 \times 10^{6}\right.$ counts per $100 \mu \mathrm{l})$ ). After coverslipping, sections were placed in an incubation chamber that was sealed with tape and parafilm and incubated overnight at $55^{\circ} \mathrm{C}$. For each case, two sections were treated with the sense probe to measure nonspecific binding. Next day, coverslips were removed and slides were washed in a bath of 
$4 \times$ saline-sodium citrate $(\mathrm{SSC}), \mathrm{pH} 7.2(1 \times \mathrm{SSC}=0.15 \mathrm{M}$ sodium chloride, $0.015 \mathrm{M}$ SSC, $\mathrm{pH} 7.2$ ) with $0.2 \%$ $\beta$-mercaptoethanol for $15 \mathrm{~min}$ and again in $4 \times \mathrm{SSC}$ for $15 \mathrm{~min}$. Sections were then washed in formamide buffer containing a $1: 1$ ratio of formamide to formamide buffer (0.6 M NaCl, $0.04 \mathrm{M}$ tris base, $2 \mathrm{mM}$ EDTA, $0.02 \mathrm{~N} \mathrm{HCl}, \mathrm{pH}$ 7.7) for $20 \mathrm{~min}$ at $55^{\circ} \mathrm{C}$. The sections were washed in $2 \times \mathrm{SSC}$ and then incubated in RnaseA solution $(10 \mathrm{mg} / \mathrm{ml}$ RNaseA in $0.5 \mathrm{M} \mathrm{NaCl} / 10 \mathrm{mM}$ Tris Base/ $1 \mathrm{mM}$ EDTA) for $30 \mathrm{~min}$ at $37^{\circ} \mathrm{C}$ to reduce the background due to nonhybridized probes. The sections were then passed through the following washes, each for $5 \mathrm{~min}$ at room temperature: $2 \times$ SSC, $1 \times$ SSC, and $0.5 \times$ SSC. One high-stringency wash was performed in $0.1 \times \mathrm{SSC}$ for $30 \mathrm{~min}$ at $55^{\circ} \mathrm{C}$ and cooled for $5 \mathrm{~min}$ in the same buffer. Sections were dipped briefly in $60 \%$ ethanol $/ 0.33 \%$ ammonium acetate, dried, and exposed to autoradiography film (Biomax $\mathrm{MR}$, Kodak) with ${ }^{14} \mathrm{C}$ calibration standard slides (ARC-146, 146A, American Radiolabeled Chemicals, Inc.) for 3 days. After development of films, sections were dipped in photographic emulsion (Kodak NTB-2) to develop silver grains.

\section{Imaging and Densitometry of In Situ Hybridization Autoradiograms}

Methods for semiquantification of in situ hybridization autoradiograms have been previously described (Arango et $a l, 2001)$ and are summarized here. Briefly, autoradiograms of each section were digitized using an image analysis system (MCID Elite; Imaging Research Inc., St Catherine's, Ontario, Canada). Two analytical approaches were taken. First, densitometric measurements of the DRN and MRN were taken from sections by outlining the raphe nuclei. Contours of the DRN and MRN were constructed from images of adjacent $\left[{ }^{3} \mathrm{H}\right] \mathrm{OH}-\mathrm{DPAT}$ receptor autoradiograms (Arango et al, 2001). These contours were then digitally overlaid on TPH2 in situ hybridization images for densitometric quantitation. A schematic of the sampled subnuclei is shown in Figure 1. Anatomical descriptions based on Nissl stains of the DRN (Baker et al, 1990) were used as a guide to delineate the subnuclei in the images of $\left[{ }^{3} \mathrm{H}\right] \mathrm{OH}$ DPAT autoradiograms. The subnuclei of the DRN include the dorsal (DRd), ventral (DRv), ventrolateral (DRvl), interfascicular (DRif), and caudal (DRc) subdivisions. The MRN was identified at its most rostral point by the presence of the decussation of the superior cerebellar peduncle in adjacent Nissl-stained sections (Baker et al, 1991a; Törk and Hornung, 1990).

Second, DRN measurements were made using a circle of fixed area $\left(80 \mathrm{~mm}^{2}\right)$ as shown in Figure 3a. A separate circle of the same size was used to measure the MRN. For all measurements taken with fixed area circles, the target area within the circle was defined so that pixels at or below background levels and pixels at or above saturation levels were excluded from the sample measurement. The measurements taken included: the area of the circle, the area of the target within the circle, the concentration of label within the circle, and the concentration of label within the target. The amount of TPH2 mRNA reported here reflects the mean concentration of TPH2 within the target in the circle and is therefore not diluted or biased by unlabeled areas. Rather, this definition of DRN results in a more restricted 'contour' of the DRN than that is derived from the distribution of the $5-\mathrm{HT}_{1 \mathrm{~A}}$ autoreceptor. Measurements from film background and non-raphe tissue section background with the same fixed area circle determined levels of nonspecific labeling.

Optical density measurements were calibrated using ${ }^{14} \mathrm{C}$ standard slides (American Radiolabeled Chemicals, Inc., ARC-146 and ARC-146A) that were coexposed with the ${ }^{35} \mathrm{~S}$ labeled tissue sections on each film. The linear relationship between ${ }^{14} \mathrm{C}$ and ${ }^{35} \mathrm{~S}$ (Miller, 1991) allowed the use of these standards for the semiquantitative analysis of the amount of ${ }^{35}$ S-labeled mRNA. Relative optical density measurements of the ${ }^{14} \mathrm{C}$ standards were obtained and plotted against the tissue radioactivity equivalents ( $\mathrm{nCi} / \mathrm{g}$ of tissue). Tissue radioactivity equivalents were adjusted for incorporation of radioactivity into the batch of riboprobe that was labeled for each experiment as an estimate of the specific activity of the labeled probe. A threshold level for each film was set so that only pixels above background and below saturation levels were included in the final measurement within the circle.

\section{Statistical Analyses}

The difference in TPH2 mRNA expression between controls and suicides was calculated using percent of control for each pair and then testing the significance with a onesample $t$-test. Expression along the anteroposterior axis was determined by averaging the densities across approximately $2 \mathrm{~mm}$ intervals for each case and then calculating the mean percent of control within each interval. The TPH2 mRNA expression in DRN subnuclei was examined using an ANOVA.

\section{RESULTS}

\section{TPH2 mRNA Expression in the DRN and MRN}

Specific, robust expression of TPH2 mRNA was observed in the DRN and MRN throughout the rostrocaudal extent of these nuclei (shown in Figure 2). TPH2 mRNA expression was also observed in the adjacent supralemniscal nuclei (B9) known to have serotonin-synthesizing neurons (Baker et al, 1991b). At the microscopic level, emulsion-dipped slides revealed that TPH2 is expressed within raphe neurons (Figure 3c). Sense sections generated a homogeneous gray film background (Figure $3 \mathrm{~b}$ ) and emulsion-dipped sense sections had few silver grains in the background and no indication of specific labeling (Figure 3d). TPH2 mRNA density levels correlated with TPH protein in a subset of cases that had previously been reacted for PH8 immunoautoradiography (Boldrini et al, 2005). In a mixed model with TPH protein as the dependent variable, TPH2 as the independent, and pair, probe, and subject as random effects, the estimate of the TPH2 effect was 0.23 with standard error $=0.058(p=0.01)$.

Densitometry readings obtained from DRN contours correlated with fixed circle measurements $(r=0.96$ in controls and $r=0.94$ in suicides; $p<0.01$ ). In controls, the mean TPH2 optical density for anatomical levels within the DRN was rostral $>$ mid-raphe $>$ caudal raphe. A negative 

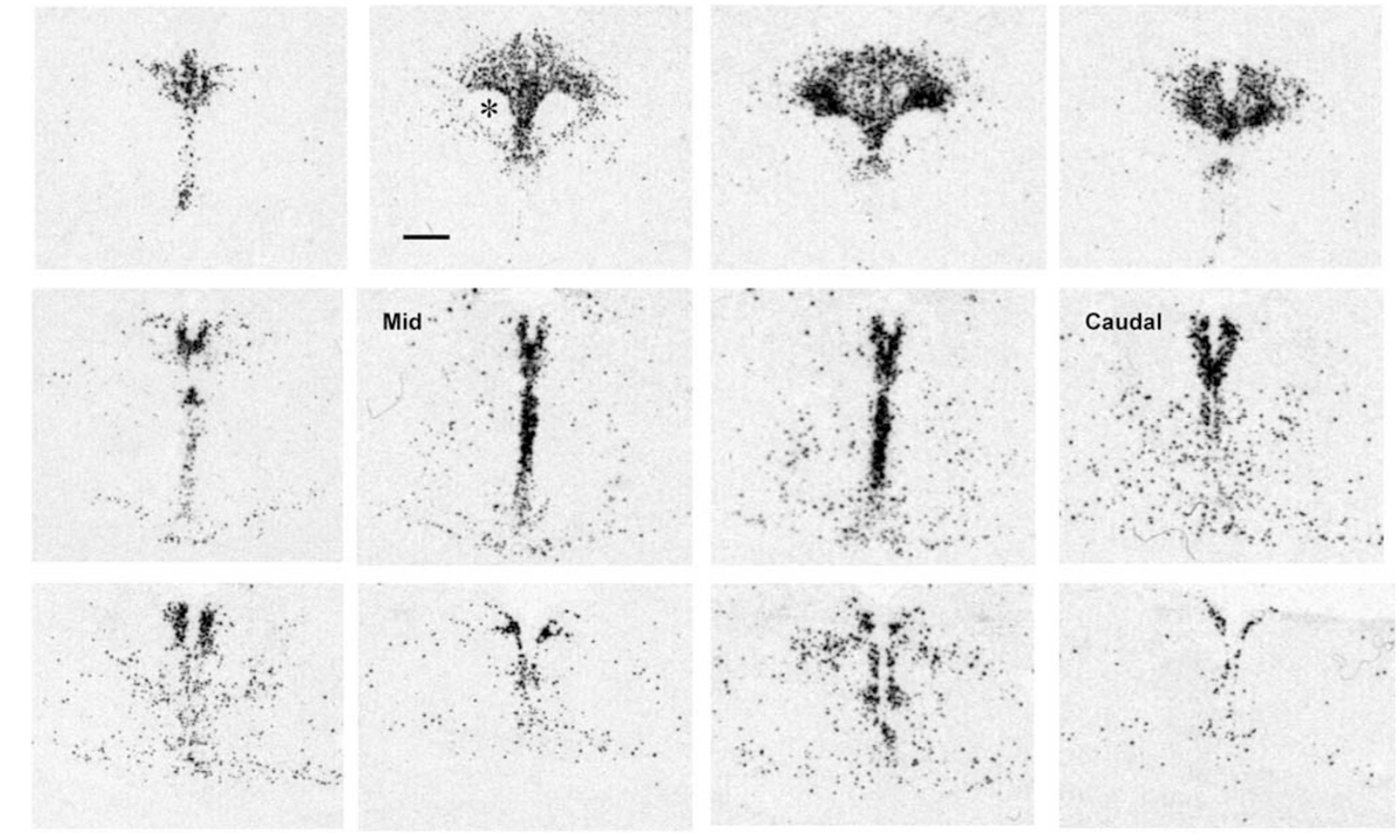

Figure 2 Autoradiograms of TPH2 mRNA distribution by in situ hybridizaton of representative brainstem sections along the anteroposterior axis of a single case. Note that the labeling is anatomically restricted and most dense in regions corresponding to the DRN and MRN. Sections spanning the mid and caudal levels of the DRN are representative of those sections selected from all cases for comparison of controls and suicides. The TPH2 in DRN is localized posterior to the medial longitudinal fasciculus (*). Bar $=2 \mathrm{~mm}$.

correlation was found with age such that TPH2 mRNA expression decreases with increasing age $(r=-0.429$, $n=22, p=0.046$ ) (Figure 4). TPH2 expression levels in females $(n=4)$ did not differ from males $(n=18)(13.5 \pm 2.5$ vs $10.3 \pm 0.7 \mathrm{nCi} / \mathrm{g} ; F=3.441, p=0.078)$. TPH2 expression did not correlate with PMI, brain $\mathrm{pH}$, or freezer storage time ( $p>0.05$, data not shown). TPH2 also showed no correlation with estimated time of death or season of death.

\section{TPH2 mRNA Expression in the DRN and MRN of Controls and Suicides}

The area of the DRN, as defined by TPH mRNA expression, at each rostrocaudal level is not different between groups (Figure 5, $p>0.05$ ). The volume of the DRN, determined by the summed area of TPH2 expression along the anteroposterior axis, is also not different (C: $46.7 \pm 6.7 v s$ S: $\left.51.6 \pm 7.9 \mathrm{~mm}^{3} ; p>0.05\right)$. Film densitometric quantification of TPH2 mRNA revealed higher TPH2 expression levels in the DRN of depressed suicides cases compared with matched controls. When two levels of the raphe (labeled mid and caudal, respectively, in Figure 2) from each case of all 11 pairs were assayed together and averaged, 33\% more TPH2 mRNA expression was found in suicides compared with matched controls in the DRN $(t=-2.421, \mathrm{df}=10$, $p=0.03$, C: $9.31 \pm 0.9$ vs S: $12.42 \pm 1.1 \mathrm{nCi} / g$; see Table 2$)$ and
$17 \%$ more in the MRN $(t=-2.168, \mathrm{df}=21, p=0.04, \mathrm{C}$ : $6.40 \pm 0.6$ vs S: $7.5 \pm 0.4 \mathrm{nCi} / \mathrm{g})$.

To compare TPH2 expression along the entire DRN, each matched pair was assayed individually and the difference expressed as a percent of control every $2.4 \mathrm{~mm}$ interval along the rostrocaudal axis. A repeated-measures ANOVA analysis revealed no significant differences in the change in $\mathrm{TPH} 2$ expression across the rostrocaudal axis. The highest difference is observed in midcaudal levels $(10-14 \mathrm{~mm}$ for the DRN and $8-10 \mathrm{~mm}$ of the MRN see Figure 6). The mean difference of $30 \%$ found at this midcaudal level of the DRN is comparable to the anatomical level and difference observed in the previously described experiment examining the midcaudal level in all subjects simultaneously. Using the measurements from the experiment in which each pair was assayed individually, we further calculated the mean percent difference in the DRN and MRN for each pair when all sections were included. Taking the average of the percent difference of each pair resulted in a mean change of $18 \%$ $(t=3.089, \mathrm{df}=5, p=0.03)$ in the DRN and $39 \%$ in the MRN. However, in the MRN this change was not statistically significant.

To determine whether the increase in TPH2 expression is specific to particular subdivisions of the DRN, density measurements were taken from five subnuclei (DRd, DRvl, DRv, DRif, and DRc). Significant differences were not detected in any individual subnucleus $(136 \%$ of control in the DRd; $133 \%$ in the DRvl; $86 \%$ in the DRv; $105 \%$ in the 

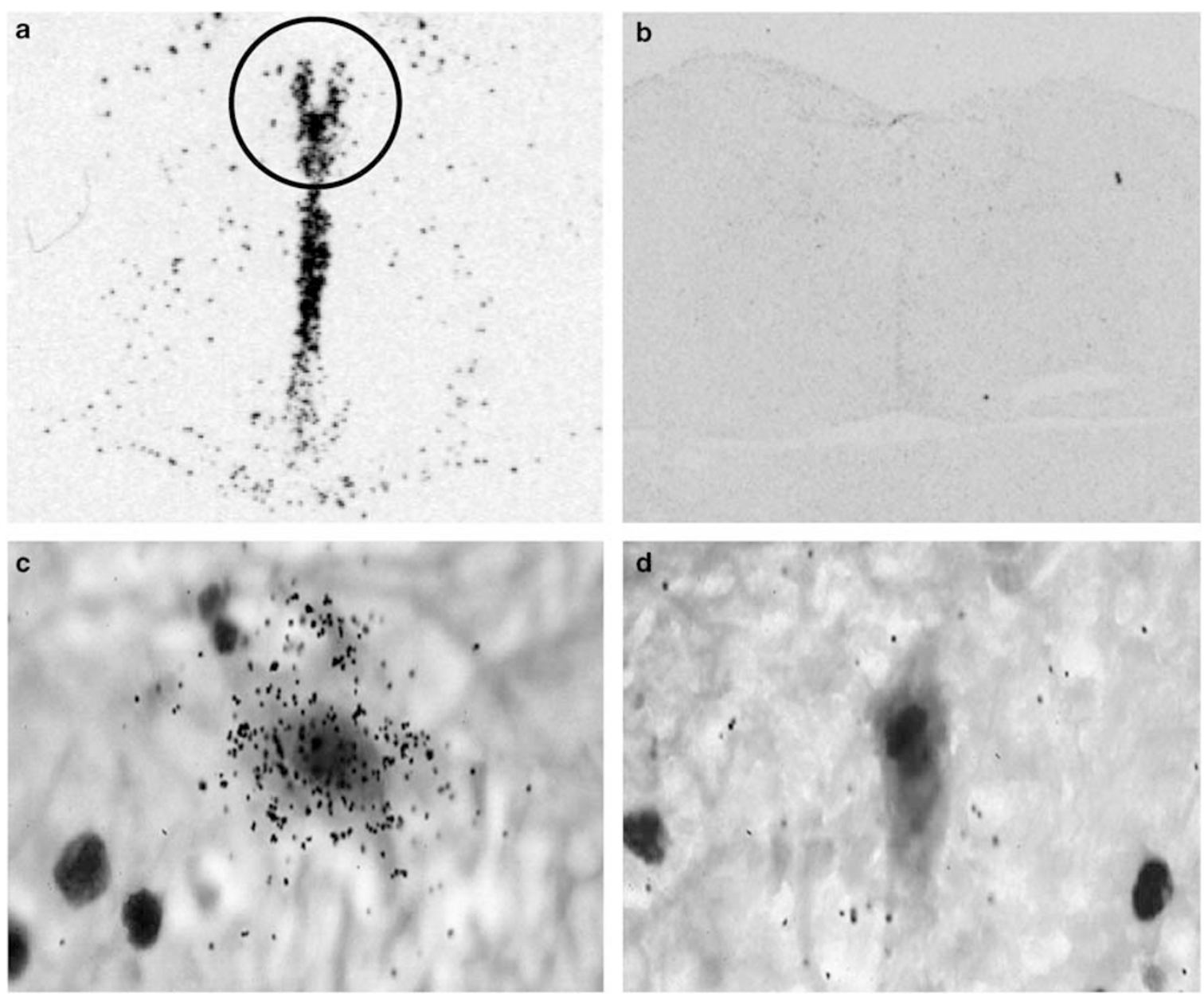

Figure 3 (a) An in situ hybridization autoradiogram with the antisense TPH2 probe in a representative human brainstem section. The circle shown encompassing the DRN was used for densitometric analysis of TPH2 expression. The area of this circle $\left(80 \mathrm{~mm}^{2}\right)$ remained unchanged for all sections measured. (b) An autoradiogram of an adjacent section to (a) that was reacted with the sense TPH2 riboprobe. Note the absence of specific labeling. (c, d) High-power photomicrographs of DRN serotonergic neurons found in TPH2 antisense (c) and sense (d) emulsion-dipped sections. Silver grains are specific to neurons and are absent in neurons in sense sections.

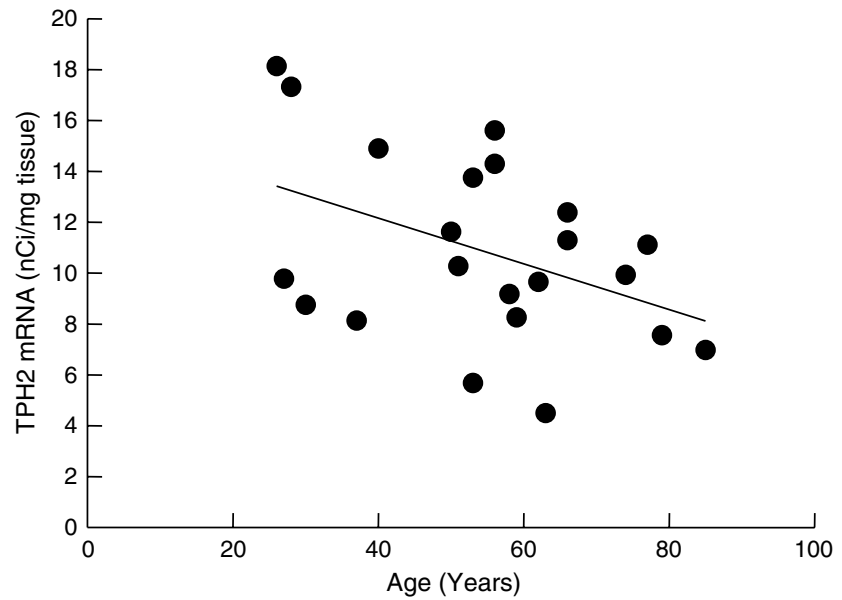

Figure 4 Relationship between TPH2 mRNA density and age. Note that TPH2 mRNA expression decreases with increasing age $(r=-0.049$, $p<0.05, n=22$ ).

DRif; and $108 \%$ in the DRc), suggesting that the difference between controls and suicides is distributed across the rostrocaudal extent of the DRN involving each subnucleus.

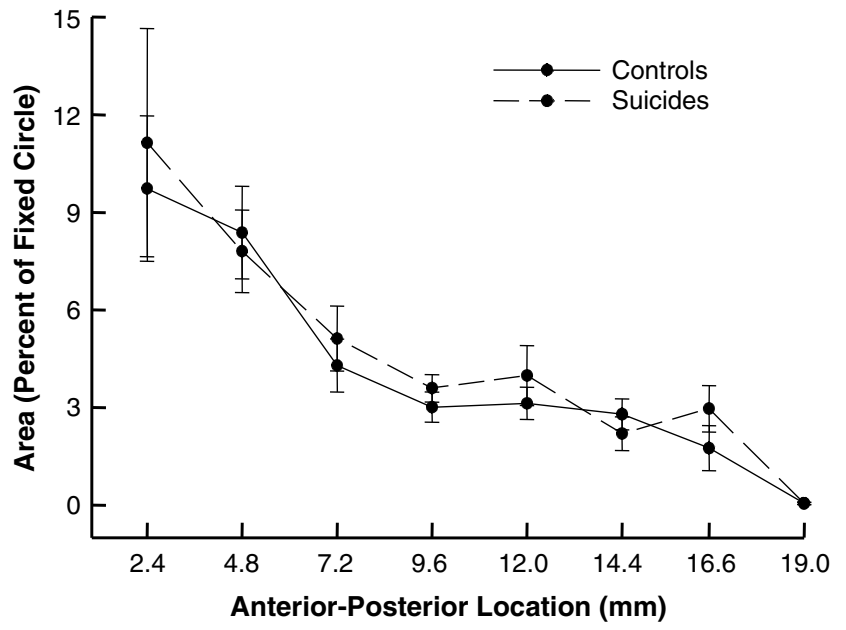

Figure 5 Area of the DRN defined by TPH2 mRNA expression in controls (solid line) and suicides (dashed line) along the rostrocaudal axis. Area is defined as a percentage of the fixed area $\left(80 \mathrm{~mm}^{2}\right)$ sampling circle.

The relatively larger 36 and 33\% increases in the DRd and the DRvl in suicides may indicate a more pronounced involvement of these subnuclei. 
Table 2 Mean TPH2 mRNA Expression in Mid and Caudal Levels of the DRN/MRN of Controls vs Suicides

\begin{tabular}{lcccc}
\hline Pair \# & $\begin{array}{c}\text { Control DRN } \\
\text { (nCi/mg) }\end{array}$ & $\begin{array}{c}\text { Suicide DRN } \\
\text { (nCi/mg) }\end{array}$ & $\begin{array}{c}\text { Control MRN } \\
\text { (nCi/mg) }\end{array}$ & $\begin{array}{c}\text { Suicide MRN } \\
\text { (nCi/mg) }\end{array}$ \\
\hline 1 & 4.50 & 12.38 & 4.05 & 6.74 \\
2 & 8.75 & 18.13 & 5.70 & 8.72 \\
3 & 11.11 & 7.56 & 6.78 & 10.01 \\
4 & 9.78 & 17.32 & 7.27 & 7.28 \\
5 & 10.27 & 11.29 & 10.38 & 7.48 \\
6 & 13.74 & 11.62 & 7.22 & 8.86 \\
7 & 8.13 & 14.89 & 5.26 & 6.55 \\
8 & 6.98 & 9.93 & 5.51 & 6.11 \\
9 & 5.68 & 8.25 & 3.88 & 6.17 \\
10 & 9.17 & 9.65 & 6.45 & 6.19 \\
11 & 14.29 & 15.60 & 7.87 & 8.49 \\
Mean & 9.31 & 12.42 & 6.40 & 7.51 \\
SEM & 0.92 & 1.09 & 0.56 & 0.40 \\
\hline
\end{tabular}
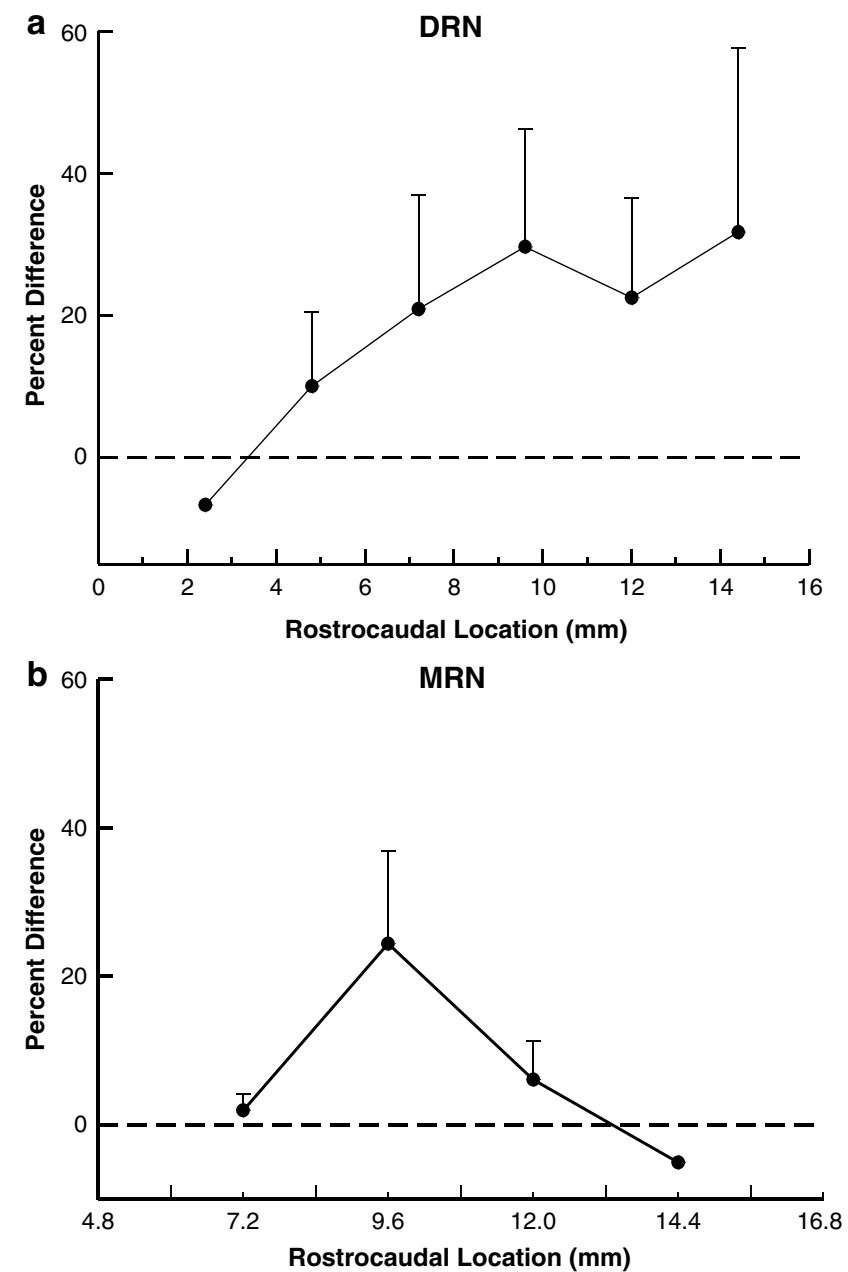

Figure 6 Difference in TPH2 expression between suicides and controls across the rostrocaudal axis of the DRN (a) and MRN (b). Difference in expression is determined as the mean of percent of control of each pair at $2.4 \mathrm{~mm}$ intervals across the rostrocaudal axis.

\section{DISCUSSION}

We show, for the first time, that expression of TPH2 mRNA in the human DRN and MRN is specific and robust. In the human brainstem, TPH2 mRNA expression was present only in the DRN-, MRN-, and supralemniscal serotoninsynthesizing nuclei and, for example, was not observed in the adjacent locus coeruleus, which contains noradrenergic neurons. These results are consistent with data from rodents (Patel et al, 2004; Zhang et al, 2004) and suggests that the neuronal TPH transcript (TPH2) is the isoform responsible for the production of the serotonin biosynthetic enzyme TPH in the human brain.

We have confirmed our finding of higher TPH immunoreactivity in a second cohort of suicides and controls using immunoautoradiography (Boldrini et al, 2005). In the present study, we report higher gene expression of TPH2 mRNA, the neuronal isoform of TPH, in the DRN of depressed suicides compared with nonpsychiatric controls. In a subset of cases in which both TPH immunoreactivity and TPH2 mRNA were assayed and measured in adjacent sections, we found that TPH2 mRNA and TPH-IR have comparable anatomical distributions within the DRN and MRN, with greater density of expression in the rostral part of the DRN complex. Our subsample, showing a correlation of TPH2 mRNA and TPH-IR that is similar in direction and magnitude across the rostrocaudal axis, suggests a functional relationship between transcript and protein levels where greater amounts of TPH2 gene expression may account for higher levels of DRN TPH-IR in depressed suicides (Boldrini et al, 2005; Underwood et al, 1999). This is further supported by our previous finding that volume of the DRN, as defined by TPH immunoreactivity, does not differ between suicides and controls (Underwood et al, 1999) and also does not differ when defined by TPH2 mRNA expression.

Previously, we reported greater number and density of TPH immunoreactive neurons in the DRN of suicides compared with controls (Underwood et al, 1999). In other studies, fewer number of neurons have been found in the DRvl subnucleus of patients with mood disorder (Baumann et al, 2002), and no change in TPH protein expression in any DRN subdivision of depressed suicides (Bonkale et al, 2004). A confounding factor of the first study is that DRN neurons were identified by a Nissl stain, and therefore included DRN cell types that are not serotonergic. In the second study, a failure to find a change in any particular subdivision of the DRN may represent a cumulative change spread throughout the subnuclei that could only be detected when the DRN is assayed as a whole. Bonkale et al (2004) examined only two levels of the DRN, thereby potentially missing changes in TPH across the rostrocaudal axis that may not be specific to DRN subdivisions. In our study, we provide evidence for an increase in TPH2 mRNA expression in suicides that is spread throughout the length of the DRN and MRN and is not restricted to any individual subnucleus, thereby lending support for the previous findings where individual levels were assayed.

Having found that both TPH protein and gene expression are increased in depressed suicides, the question remains as to why. In rats, TPH protein and mRNA are elevated in response to stress (Azmitia et al, 1993; Chamas et al, 1999, 
2004), suggesting that depression and suicide-related stress may account for elevated TPH gene expression and protein. Alternatively, the serotonergic system may be altered as part of a homeostatic response to deficient serotonin levels in depressed suicides. There is an apparent paradox, namely we find more serotonin neurons, higher gene expression, and more TPH-IR (protein), and, yet, previous studies report less serotonin and/or 5-HIAA in the midbrain of suicides (reviewed by Mann et al, 1989) and in the CSF of suicide attempters (Placidi et al, 2001). The leading hypothesis regarding the pathophysiology of major depression and suicide is a deficiency in serotonergic neurotransmission (Arango et al, 2001; Mann, 2003). Greater TPH2 gene expression in the DRN of depressed suicides may be a compensatory mechanism for deficient brain serotonin levels or serotonergic neurotransmission to target areas. Lower levels of serotonin could result from impaired biosynthetic capacity of the TPH enzyme. A variant in the TPH gene has been recently found (Zhang et al (2004) in mice and Zhang et al (2005) in humans) that results in lower levels of serotonin synthesis in vitro although the reported mutation was present in only $10 \%$ of the major depressive disorder (MDD) cases studied and these cases were mostly suicide attempters (Zhang et al, 2005). Other potential polymorphisms (Zill et al, 2004) or enzyme defects affecting TPH2 catalytic activity could explain deficient serotonergic synthesis in other cases of MDD or suicide. Furthermore, the finding that high levels of TPH2 are present throughout the rostrocaudal extent of the DRN and may be specific to particular rostral subnuclei suggests that finer targets within the dorsolateral prefrontal cortex may be implicated in depression and suicide. The prefrontal cortex is found to have alterations in serotonin receptor binding (Arango et al, 2001) and is implicated as a site involved in the pathophysiology of MDD. Heterogeneous changes in DRN with more pronounced changes in subnuclei with neurons providing the serotonergic innervation to target regions implicated in the disorder suggest aberrant circuits or inadequate homeostatic compensatory responses that are specific and targeted and not global and divergent.

The analysis of TPH2 expression was examined in two types of experiments; one assayed two anatomical levels from each case in one single large experiment, and the second assayed all levels across the rostrocaudal axis of the DRN. The first approach lacked anatomical precision, but allowed the simultaneous assay of all cases under identical conditions. This experiment removed the possibility of variability that could not be controlled when individually analyzing each pair. Furthermore, since only one sheet of autoradiographic film was used for this experiment, we could directly measure and compare TPH2 expression levels across the 11 pairs. This experiment confirmed the difference in TPH2 expression between controls and suicides in direction and magnitude. In the second experiment, TPH2 mRNA expression was quantified within a fixed area circle, an index of the total amount of TPH2 in the DRN or MRN and a contour, a measure of the concentration of TPH2. DRN subnuclei contours provided anatomical definition that a fixed area circle did not. Results from both the fixed area circle ROI and anatomical contouring of the entire DRN for the densitometric analysis of TPH2 expression were highly correlated. Furthermore, the fixed circle ROI measurements did not underestimate the amount of TPH2, an indication that the partial volume effect seen with in vivo positron emission tomography (PET) scanning does not apply to this film-based method.

The change in TPH2 expression was found across the entirety of the anteroposterior axis of the DRN. Analysis of individual DRN subnuclei and the lack of statistically significant differences in any single subnucleus support the notion that TPH2 mRNA expression is distributed throughout the DRN. Studies on cortical innervation of the DRN in macaques demonstrate that there is a rough rostrocaudal topographic organization between dorsal raphe neurons and their cortical terminations. For example, the dorsolateral prefrontal cortex is predominantly innervated by the rostral DRN, while primary somatosensory and primary visual cortices are innervated predominantly by neurons from the caudal DRN (Wilson and Molliver, 1991b). The implication of a widespread increase in TPH2 expression in the DRN is that serotonin alterations in target regions likely extend beyond the prefrontal cortex. More specific DRN alterations such as increased TPH2 expression in particular subnuclei would be suggestive of comparatively greater effects in select targets such as the prefrontal cortex. A caveat is that the homology of projections between nonhuman and human primates remains unknown.

The finding of greater TPH2 gene expression in the DRN of depressed suicides cannot be explained by differences in demographic variables, brain $\mathrm{pH}$, or storage effects between controls and suicides, since this study used a matched, pairwise case-control design. Furthermore, brain toxicology screens show that all subjects were free from drugs or medications. Although we cannot rule out previous effects of antidepressants that were stopped long enough before death, so as to be no longer detectable, the informants interviewed for the psychological autopsy revealed that the majority of cases did not receive treatment in the 3 months before death. Only four depressed subjects were reported to have received prescriptions for psychotropic medication in the 3 months before death (SSRIs, $n=2$; mood stabilizers, $n=1$, tricyclic antidepressants, $n=1$ ), but none tested positive for these drugs at death, suggesting that they had discontinued the medication earlier or never taken it. Like the group as a whole, these four depressed cases also had higher levels of TPH2 mRNA compared to controls. Therefore, higher TPH2 mRNA levels in depressed suicides are likely associated with a pre-existing mood disorder and/ or suicidal behavior. Further studies are required to determine the effects of antemortem treatments on TPH2 expression.

The incidence of suicide and depression is known to increase in the later decades of life in males (www.cdc.gov/ ncipc/wisqars 2002). Serotonergic receptor binding in the cortex, specifically $5 \mathrm{HT}_{1 \mathrm{~A}}, 5 \mathrm{HT}_{1 \mathrm{~B} / \mathrm{D}}$, and $5 \mathrm{HT}_{2 \mathrm{~A}}$, has been found to be decreased postmortem in elderly suicides and some of these findings have been confirmed in depressed elderly patients in PET studies (Meltzer et al (1998b) and also reviewed in Meltzer et al (1998a)). Therefore, it is likely that changes in serotonergic neurotransmission that are associated with depression and suicide are only exacerbated in the elderly. The observation of decreased TPH2 with age raises the possibility that changes in TPH2 mRNA 
expression may also contribute to the risk for depression or suicide in elderly males.

In the study of suicide and mood disorders in postmortem human brain, it is necessary to distinguish the molecular pathophysiology of major depression from that of the diathesis for suicide. The results of this study need to be replicated and extended in a larger series of cases that includes a sufficient number of suicides without major depression to separate the effects of major depression from suicide. Future studies should also determine the expression level per cell by grain-counting of emulsion-dipped slides to determine whether higher levels of expression are a function of more serotonin neurons or whether expression per neuron is greater. Such studies should be combined with assays in which the biosynthetic capacity of TPH can be tested so as to link higher gene expression with a functional outcome which would ultimately lead to deficient levels of brain serotonin. For example, functional mutations in the $\mathrm{TPH}$ catalytic site may result in a low-activity enzyme. Alternatively, assays measuring changes in postmortem TPH activity in the presence of limiting cofactors such as oxygen, pteridines, or ferrous iron can be conducted to determine whether all the molecular machinery is in place for the efficient function of TPH. Another possible avenue is measuring the level of endogenous TPH inhibitors that could decrease the efficacy of the enzyme. Taken together, these speculations provide a framework for future directions of studies that may interlace changes in TPH2 gene expression with low serotonin levels in depression and suicide.

\section{ACKNOWLEDGEMENTS}

This work was supported by MH40210, MH62185, MH64168 grant, The Diane Goldberg Foundation, and the American Foundation for Suicide Prevention. We thank Jennifer Lau for her work with image analysis, sampling and quantification. We also thank Stephen P Ellis who provided expertise with statistical analyses.

\section{REFERENCES}

Arango V, Underwood MD, Boldrini M, Tamir H, Kassir SA, Hsiung $S$ et al (2001). Serotonin 1A receptors, serotonin transporter binding and serotonin transporter mRNA expression in the brainstem of depressed suicide victims. Neuropsychopharmacology 25: 892-903.

Arango V, Underwood MD, Gubbi AV, Mann JJ (1995). Localized alterations in pre- and postsynaptic serotonin binding sites in the ventrolateral prefrontal cortex of suicide victims. Brain Res 688: 121-133.

Austin MC, O'Donnell SM (1999). Regional distribution and cellular expression of tryptophan hydroxylase messenger RNA in postmortem human brainstem and pineal gland. J Neurochem 72: 2065-2073.

Azmitia EC, Liao B, Chen YS (1993). Increase of tryptophan hydroxylase enzyme protein by dexamethasone in adrenalectomized rat midbrain. J Neurosci 13: 5041-5055.

Baker KG, Halliday GM, Halasz P, Hornung JP, Geffen LB, Cotton RG et al (1991a). Cytoarchitecture of serotonin-synthesizing neurons in the pontine tegmentum of the human brain. Synapse 7: $301-320$.
Baker KG, Halliday GM, Hornung JP, Geffen LB, Cotton RG, Tork I (1991b). Distribution, morphology and number of monoaminesynthesizing and substance P-containing neurons in the human dorsal raphe nucleus. Neuroscience 42: 757-775.

Baker KG, Halliday GM, Törk I (1990). Cytoarchitecture of the human dorsal raphe nucleus. J Comp Neurol 301: 147-161.

Baumann B, Bielau H, Krell D, Agelink MW, Diekmann S, Wurthmann C et al (2002). Circumscribed numerical deficit of dorsal raphe neurons in mood disorders. Psychol Med 32: 93-103.

Boldrini M, Underwood MD, Mann JJ, Arango V (2005). More tryptophan hydroxylase in the brainstem dorsal raphe nucleus in depressed suicides. Brain Res 1041: 19-28.

Bonkale WL, Murdock S, Janosky JE, Austin MC (2004). Normal levels of tryptophan hydroxylase immunoreactivity in the dorsal raphe of depressed suicide victims. J Neurochem 88: 958-964.

Chamas F, Serova L, Sabban EL (1999). Tryptophan hydroxylase mRNA levels are elevated by repeated immobilization stress in rat raphe nuclei but not in pineal gland. Neurosci Lett 267: $157-160$.

Chamas FM, Underwood MD, Arango V, Serova L, Kassir SA, Mann JJ et al (2004). Immobilization stress elevates tryptophan hydroxylase mRNA and protein in the rat raphe nuclei. Biol Psychiatry 55: 278-283.

Clark MS, Russo AF (1997). Tissue-specific glucocorticoid regulation of tryptophan hydroxylase mRNA levels. Brain Res $\mathrm{Mol}$ Brain Res 48: 346-354.

Dulchin MC, Oquendo MA, Malone KM, Ellis SP, Li S, Mann JJ (2001). Prolactin response to DL-fenfluramine challenge before and after treatment with paroxetine. Neuropsychopharmacology 25: 395-401.

First MB, Spitzer RL, Gibbon M, Williams JMG, Benjamin L (1996). Structured Clinical Interview for DSM-IV Axis II Personality Disorders (SCID-II) (Version 2.0). Biometrics Research Department, New York State Psychiatric Institute: New York, 49pp.

Harrison PJ, Heath PR, Eastwood SL, Burnet PWJ, McDonald B, Pearson RCA (1995). The relative importance of premortem acidosis and postmortem interval for human brain gene expression studies: selective mRNA vulnerability and comparison with their encoded proteins. Neurosci Lett 200: 151-154.

Hrdina PD, Demeter E, Vu TB, Sótónyi P, Palkovits M (1993). 5$\mathrm{HT}$ uptake sites and $5-\mathrm{HT}_{2}$ receptors in brain of antidepressantfree suicide victims/depressives: increase in $5-\mathrm{HT}_{2}$ sites in cortex and amygdala. Brain Res 614: 37-44.

Kelly TM, Mann JJ (1996). Validity of DSM-III-R diagnosis by psychological autopsy: a comparison with clinician ante-mortem diagnosis. Acta Psychiatr Scand 94: 337-343.

Malone KM, Corbitt EM, Li S, Mann JJ (1996). Prolactin response to fenfluramine and suicide attempt lethality in major depression. Br J Psychiatry 168: 324-329.

Mann JJ (2003). Neurobiology of suicidal behaviour. Nat Rev Neurosci 4: 819-828.

Mann JJ, Arango V, Marzuk PM, Theccanat S, Reis DJ (1989). Evidence for the 5-HT hypothesis of suicide. A review of postmortem studies. Br J Psychiatry 155(Suppl 8): 7-14.

Mann JJ, Huang YY, Underwood MD, Kassir SA, Oppenheim S, Kelly TM et al (2000). A serotonin transporter gene promoter polymorphism (5-HTTLPR) and prefrontal cortical binding in major depression and suicide. Arch Gen Psychiatry 57: 729-738.

Meltzer CC, Smith G, DeKosky ST, Pollock BG, Mathis CA, Moore RY et al (1998a). Serotonin in aging, late-life depression, and Alzheimer's disease: the emerging role of functional imaging. Neuropsychopharmacology 18: 407-430.

Meltzer CC, Smith G, Price JC, Reynolds III CF, Mathis CA, Greer P et al (1998b). Reduced binding of [18F]altanserin to serotonin type 2A receptors in aging: persistence of effect after partial volume correction. Brain Res 813: 167-171. 
Miller JA (1991). The calibration of ${ }^{35} \mathrm{~S}$ or ${ }^{32} \mathrm{P}$ with ${ }^{14} \mathrm{C}$-labeled brain paste or ${ }^{14} \mathrm{C}$-plastic standards for quantitative autoradiography using LKB Ultrafilm or Amersham Hyperfilm. Neurosci Lett 121: 211-214.

Pandey GN, Dwivedi Y, Rizavi HS, Ren X, Pandey SC, Pesold C et al (2002). Higher expression of serotonin 5-HT(2A) receptors in the postmortem brains of teenage suicide victims. Am J Psychiatry 159: 419-429.

Patel PD, Pontrello C, Burke S (2004). Robust and tissue-specific expression of TPH2 versus TPH1 in rat raphe and pineal gland. Biol Psychiatry 55: 428-433.

Pierce ET, Foote WE, Hobson JA (1976). The efferent connection of the nucleus raphe dorsalis. Brain Res 107: 137-144.

Placidi GP, Oquendo MA, Malone KM, Huang YY, Ellis SP, Mann JJ (2001). Aggressivity, suicide attempts, and depression: relationship to cerebrospinal fluid monoamine metabolite levels. Biol Psychiatry 50: 783-791.

Placidi GPA, Oquendo MA, Malone KM, Brodsky B, Ellis SP, Mann JJ (2000). Anxiety in major depression: relationship to suicide attempts. Am J Psychiatry 157: 1614-1618.

Spitzer RL, Williams JBW, Gibbon M, First MB (1992). The Structured Clinical Interview for DSM-III-R (SCID). I: History, rationale, and description. Arch Gen Psychiatry 49: 624-629.

Stockmeier CA, Shapiro LA, Dilley GE, Kolli TM, Friedman L, Rajkowska G (1998). Increase in serotonin-1A autoreceptors in the midbrain of suicide victims with major depression-postmortem evidence for decrease serotonin activity. J Neurosci 18: 7394-7401.

Törk I (1990). Anatomy of the serotonergic system. Ann NY Acad Sci 600: 9-35.

Törk I, Hornung J-P (1990). Raphe nuclei and the serotonergic system. In: Paxinos G (ed). The Human Nervous System. Academic Press: San Diego. pp 1001-1022.
Turecki G, Zhu Z, Tzenova J, Lesage A, Seguin M, Tousignant M et al (2001). TPH and suicidal behavior: a study in suicide completers. Mol Psychiatry 6: 98-102.

Underwood MD, Khaibulina AA, Ellis SP, Moran A, Rice PM, Mann JJ et al (1999). Morphometry of the dorsal raphe nucleus serotonergic neurons in suicide victims. Biol Psychiatry 46: 473-483.

Walther DJ, Peter JU, Bashammakh S, Hortnagl H, Voits M, Fink H et al (2003). Synthesis of serotonin by a second tryptophan hydroxylase isoform. Science 299: 76.

Weiss D, Coccaro EF (1997). Neuroendocrine challenge studies of suicidal behavior. Psychiatr Clin North Am 20: 563-579.

Williams JBW, Gibbon M, First MB, Spitzer RL, Davies M, Borus J et al (1992). The structured clinical interview for DSM-III-R (SCID). II. Multisite test-retest reliability. Arch Gen Psychiatry 49: 630-636.

Wilson MA, Molliver ME (1991a). The organization of serotonergic projections to cerebral cortex in primates: regional distribution of axon terminals. Neuroscience 44: 537-553.

Wilson MA, Molliver ME (1991b). The organization of serotonergic projections to cerebral cortex in primates: retrograde transport studies. Neuroscience 44: 555-570.

Zhang X, Beaulieu JM, Sotnikova TD, Gainetdinov RR, Caron MG (2004). Tryptophan hydroxylase-2 controls brain serotonin synthesis. Science 305: 217.

Zhang X, Gainetdinov RR, Beaulieu JM, Sotnikova TD, Burch LH, Williams RB et al (2005). Loss-of-function mutation in tryptophan hydroxylase-2 identified in unipolar major depression. Neuron 45: 11-16.

Zill P, Baghai TC, Zwanzger P, Schule C, Eser D, Rupprecht R et al (2004). SNP and haplotype analysis of a novel tryptophan hydroxylase isoform (TPH2) gene provide evidence for association with major depression. Mol Psychiatry 9: 1030-1036. 